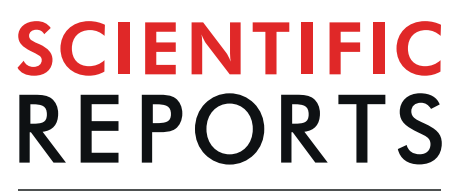

natureresearch

\title{
Trait-based community assembly of epiphytic diatoms in saline astatic ponds: a test of the stress- dominance hypothesis
}

Éva Ács ${ }^{1,2 *}$, Angéla Földi ${ }^{1,3}$, Csaba Ferenc Vad $\mathbb{B}^{4}$, Zsuzsa Trábert ${ }^{1,3}$, Keve Tihamér Kiss ${ }^{1}$, Mónika Duleba ${ }^{1,5}$, Gábor Borics ${ }^{1}$, István Grigorszky ${ }^{6}$ \& Zoltán Botta-Dukát $\mathbb{B}^{5,7}$

The stress dominance hypothesis (SDH) postulates that strong environmental gradients drive trait convergence in communities over limiting similarity. Previous studies, conducted mostly with terrestrial plant communities, found controversial evidence for this prediction. We provide here the first test for SDH for epiphytic diatoms. We studied community assembly in diatom communities of astatic ponds. These water bodies serve as a good model system for testing SDH because they exhibit stress gradients of various environmental factors. Functional diversity of diatom communities was assessed based on four traits: (1) combined trait reflecting the trade-off between stress tolerance and competitive dominance, (2) cell size, (3) oxygen requirement and (4) N-uptake strategy. According to our results, salinity, $\mathrm{pH}$ and the width of the macrophyte belt appeared as significant predictors of the trait convergence/divergence patterns presumably acting through influencing the availability of carbon dioxide and turbidity. Lower trait diversity was found in turbid, more saline and more alkaline ponds and functional diversity was higher in transparent, less saline and less alkaline ponds. Overall, our results supported the stress dominance hypothesis. In habitats representing increased environmental stress, environmental filtering was the most important community assembly rule, while limiting similarity became dominant under more favourable conditions.

Understanding the major processes driving the assembly of local communities from a regional species pool is a central topic of community ecology ${ }^{1}$. These processes operate as a series of filters ${ }^{1,2}$ including dispersal limitation, environmental suitability, and interactions between co-occurring species. The dispersal potential of small-bodied organisms, such as bacteria and protists is considered to be enormous, which suggests an insignificant role of dispersal limitation on small spatial scales ${ }^{3}$, albeit exceptions can occur ${ }^{4}$. Community assembly studies often focus on the other two filters, which are: environmental suitability and interactions among competing species. Trait-based approaches are timely tools for building a mechanistic framework for community assembly and are increasingly used, especially in terrestrial plant communities ${ }^{5}$. They are less considered in aquatic primary producers, though their huge phylogenetic diversity and related trait-differences make them highly suitable objects for applying these concepts ${ }^{6-9}$.

Environmental filtering sensu stricto determines which species of the regional species pool can establish and persist in local populations in a given habitat ${ }^{10}$ in the absence of biotic interactions. Filtering, however, is deterministic only in the sense that the environment determines the probability of the occurrence, and species with a low probability of occurrence can be regarded as filtered out ${ }^{1}$. Abiotic conditions influence not only the probability of presence but also the probability of reaching a high abundance. Since both effects on presence and abundance lead to trait convergence (i.e. a lower functional diversity than would be expected in random trait

${ }^{1}$ MTA Centre for Ecological Research, Danube Research Institute, Karolina út 29, H-1113, Budapest, Hungary. ${ }^{2}$ National University of Public Service, Faculty of Water Sciences, 6500, Baja, Bajcsy-Zsilinszky utca 12-14, Hungary. ${ }^{3}$ Doctoral School of Environmental Sciences, Eötvös Lóránd University, Budapest, Hungary. ${ }^{4}$ Wasser Cluster Lunz, Dr. Carl Kupelwieser Promenade 5, A-3293, Lunz am See, Austria. ${ }^{5}$ MTA Centre for Ecological Research, Sustainable Ecosystems Group, Klebelsberg Kuno u. 3, H-8237, Tihany, Hungary. ${ }^{6}$ University of Debrecen, Department of Hydrobiology, Egyetem tér 1., H-4032, Debrecen, Hungary. ${ }^{7}$ MTA Centre for Ecological Research, Institute of Ecology and Botany, Alkotmány u. 2-4., H-2163, Vácrátót, Hungary. *email: acs.eva@okologia.mta.hu 
assembly $)^{11,12}$, here we do not distinguish them and refer to both as environmental filtering. According to the niche theor $\mathrm{y}^{13,14}$, for robust co-existence species have to differ in their population regulation. This limiting similarity causes divergence in traits related to resource use, defence against natural enemies and other processes regulating population growth ${ }^{15}$. Both environmental filtering and limiting similarity may influence community assembly simultaneously; therefore, both trait convergence and trait divergence may occur in a given habitat depending on the type of the functional traits studied ${ }^{16-18}$.

Testing the hypotheses of how ecological processes vary along environmental gradients may reduce the likelihood of drawing incorrect conclusions from analyses of functional diversity ${ }^{19}$. Productivity and various stress gradients are those along which the functional properties of assemblages are most frequently studied. Several theories have been proposed to predict how trait convergence or divergence vary along these gradients $\mathrm{s}^{20-23}$.

The stress-dominance hypothesis (SDH) predicts that in a harsh environment habitat filtering is the major driver of community composition resulting in strong trait convergence, while limiting similarity is more important in less stressful habitats, resulting in trait divergence ${ }^{20,23,24}$. Empirical evidence for this theory from terrestrial plant or phytoplankton communities is controversial. Mason et al. ${ }^{25}$ found evidence for the increasing importance of limiting similarity in more productive environments. Other studies found the opposite, a transition in the relative contribution of trait divergence to trait convergence with increasing productivity e.g. ${ }^{17,26,27}$, which contradicts the postulate of the stress-dominance hypothesis. At the same time, these findings support Grime's ${ }^{21}$ predictions that higher productivity should lead to trait convergence because increasing competition excludes species with traits associated with weaker competitive ability. Combining the two hypotheses, Navas \& Violle ${ }^{22}$ argued that trait convergence could be expected at both ends of the productivity gradient, and trait divergence at medium productivity. Lhotsky et al. ${ }^{18}$ showed that the sign of changes along an environmental gradient might depend on the role of the studied traits: in their analysis, the pattern of the vegetative traits supported the stress-dominance hypothesis, while the pattern of the seed weight diversity contradicted it. In phytoplankton, Kruk et al. ${ }^{28}$ found evidence that on a global scale higher productivity and environmental stability lead to a smaller variance in traits.

Epiphytic diatoms are ideal objects for testing concepts on the role of environmental filtering and limiting similarity because they are small-bodied passive dispersers, frequent in aquatic environments, form an extremely diverse phylum (with more than 100,000 taxa) and well-developed methods exist for their routine microscopical identification. They have long been used as bioindicators ${ }^{29}$ because they are highly sensitive to changes in environmental conditions (e.g. nutrient concentration, salinity, $\mathrm{pH}$, turbidity) ${ }^{30}$. Based on their indication ability, benthic diatoms are widely used in ecological status assessment both in riverine and lacustrine environments ${ }^{31,32}$. To the best of our knowledge, the stress-dominance hypothesis has not yet been tested in benthic diatom communities.

As a model system for studying the assembly of epiphytic diatom communities, we have chosen a dense cluster of saline bomb crater ponds ${ }^{33}$. These ponds represent ideal sites for testing theories of community assembly along stress gradients because they are restricted in space and similar in morphology, but exhibit gradients of several environmental variables.

The salinity gradient constitutes a major factor structuring aquatic communities ${ }^{34}$. In contrast to the productivity-diversity relationship which may show different (hump-shaped, negative, positive) patterns ${ }^{35-37}$, the species richness of zooplankton in inland saline waters shows a monotonous decline with increasing salinity ${ }^{38}$. Therefore, one can expect that the relative importance of environmental filtering over limiting similarity increases with increasing salinity.

In trait-based studies of benthic (including epiphytic, epilithic, etc.) diatoms ${ }^{39}$, beyond the frequently used ecological guilds ${ }^{40,78}$ and cell size ${ }^{41}$, oxygen requirement ${ }^{30}$ and $\mathrm{N}$-uptake strategy ${ }^{30}$ could also be relevant traits.

We hypothesized that in the studied ponds the diatom species composition is predominantly determined by environmental filtering while limiting similarity has less importance in community assembly. Our aims were 1) to test the SDH in epiphytic diatom communities in sodic bomb crater ponds, which are astatic ponds with multiple stress gradients (including salinity, turbidity, $\mathrm{pH}$ ); and to reveal 2) how the relative contribution of trait convergence/divergence to community assembly depends on environmental conditions.

\section{Results}

All ponds were alkaline, and their physical and chemical properties exhibited considerable variation (see Supplementary Table S1). Significant correlations were found between continuous environmental variables, mainly between salinity, $\mathrm{pH}, \mathrm{N}: \mathrm{P}$ ratio and TP (see Supplementary Table S2). Salinity and $\mathrm{pH}$ were strongly correlated (Spearman's rho $=0.74, \mathrm{p}=3.6^{*} 10^{-9}$; see Supplementary Fig. S1), and both were high when the macrophyte belt was absent and showed a decreasing trend with the increasing width of the macrophyte belt (see Supplementary Fig. S2).

Altogether, 80 diatom taxa, representing 33 genera, were identified in the ponds. The genus Nitzschia was represented by the greatest number of species (16), followed by the genus Gomphonema (9). Mean species richness was 13.7. Species richness did not change considerably along the salinity gradient (see Supplementary Fig. S3). According to the Chi-square tests, traits were only weakly associated with each other (see Supplementary Tables S3-S8).

Considering the overall trait dispersion patterns (i.e. the effect size for all of the studied ponds irrespective of the environmental variables), trait convergence was dominant (most of the effect size values are negative) for cell size, while trait divergence was dominant for nitrogen uptake (most of the effect size values are positive). For these two traits the overall mean effect size departs significantly from zero: $\mathrm{t}=-11.583, \mathrm{p}=4.3^{*} 10^{-15}$, and $\mathrm{t}=6.1156$, $\mathrm{p}=2.1 * 10^{-7}$, respectively. Both types of departure from randomness occurred for the ecological group, and for oxygen requirement, and also when all of four traits were used to calculate functional diversity (Fig. 1). In these cases mean values do not significantly depart from zero $(t=0.95942, p=0.3425$ for ecological group; and $\mathrm{t}=-0.0655, \mathrm{p}=0.9481$ for oxygen requirement, and $\mathrm{t}=-0.90256$, $\mathrm{p}$-value $=0.3716$ for all traits together). 


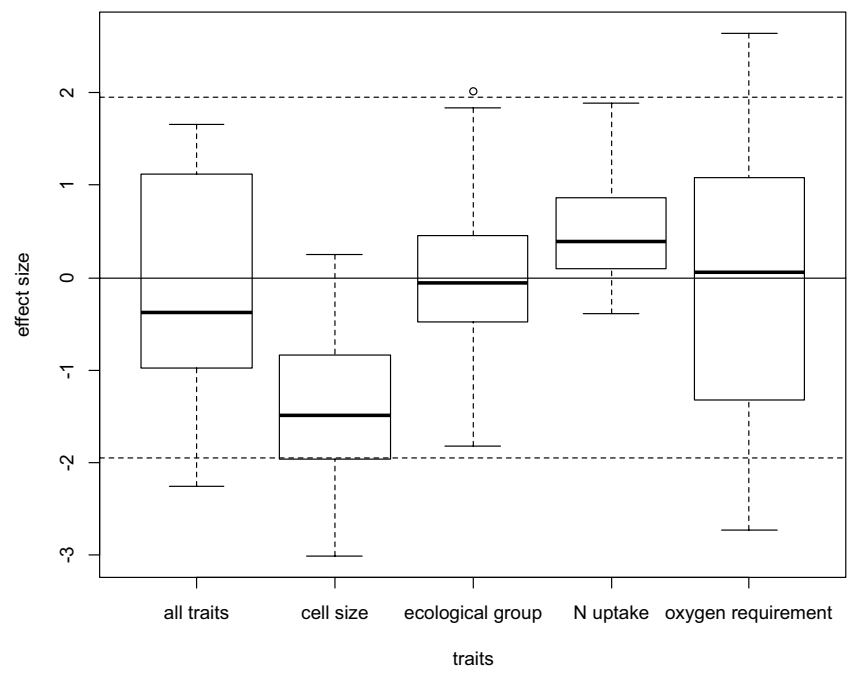

Figure 1. Box-plots of the effect sizes of each pond. A positive effect size indicates trait divergence, while a negative value indicates trait convergence. The threshold of the significant departure from zero at the 5\% significance level is marked with dashed lines. Although most of the observed values are between these dashed lines, and the individual tests are therefore non-significant, several non-significant departures with the same direction may indicate significant departures from randomness at the meta-community level.

Fitting a decision tree revealed that trait convergence in cell size was weak in low-salinity ponds (i.e. effect sizes are low in absolute values), but became strong (indicated by more negative effect sizes) if salinity exceeded $1.7 \mathrm{~g} \mathrm{~L}^{-1}$ (Fig. 2a). Macro- and very large diatoms did not reach high relative abundance, irrespective of environmental conditions (see Supplementary Table S9, Fig. 3). Low-salinity ponds (i.e. below $1.7 \mathrm{~g} \mathrm{~L}^{-1}$ ) were co-dominated by nano-, micro- and meso-sized diatoms; at high salinity (above $1.7 \mathrm{~g} \mathrm{~L}^{-1}$ ) the micro-sized group became the sole dominant group (Fig. 3).

The functional diversity of the ecological group (EG) was higher than a random expectation (trait divergence) in ponds with salinity below $2.2 \mathrm{gL}^{-1}$, while it hardly departed from a random expectation if salinity exceeded this threshold (Fig. 2b). The relative abundance of diatoms with EG4 was low in all ponds (see Supplementary Table S9, Fig. 4), while the relative abundance of the other three EG categories varied considerably, depending on salinity (Fig. 4). At low salinity (i.e. below $2.2 \mathrm{~g} \mathrm{~L}^{-1}$ ) all of the three EG categories could reach a high relative abundance; at high salinity (i.e. above $2.2 \mathrm{~g} \mathrm{~L}^{-1}$ ) diatoms with EG3 became dominant.

Regarding the N-uptake strategy, trait divergence was observed in almost all ponds, irrespective of environmental conditions.

Analysing the oxygen requirement, we found trait convergence in ponds with high $\mathrm{pH}(>8.37)$. Note that the macrophyte belt in these ponds was narrow or completely absent and the total suspended matter content was high. Effect sizes were close to zero in ponds with lower $\mathrm{pH}(<8.37)$ and with a narrow or absent macrophyte belt, while in ponds with a wide macrophyte belt and lower $\mathrm{pH}$, effect sizes indicated trait divergence (Fig. 2c).

The relative abundance of the oxybiontic species group varied in a narrow range (see Supplementary Table S9). Ponds with low $\mathrm{pH}$ and a wide macrophyte belt were dominated by poly-oxybiontic species, while in ponds with high $\mathrm{pH}$ or a narrow/missing macrophyte belt species with a moderate or low oxygen requirement were abundant (Fig. 5). The relative abundance of the two groups in these ponds was strongly negatively correlated $(\mathrm{r}=-0.935$, $\mathrm{p}<0.001$ ); thus, only one of them could be dominant in each pond.

\section{Discussion}

Although the pattern of changes varied considerably among traits, the overall picture was consistent with the $\mathrm{SDH}^{23}$, which predicts the dominance of environmental filtering under harsh conditions and the dominance of competition in more favourable habitats.

Salinity, $\mathrm{pH}$ and the width of the macrophyte belt were the three environmental variables that appeared as significant predictors of the convergence/divergence patterns. These variables were correlated, therefore we can interpret increasing salinity, increasing $\mathrm{pH}$ and decreasing width of macrophyte belts as indicators of increasing stress. This allows us to summarize the main trends of functional diversity along the stress gradient for all studied traits in a schematic figure (Fig. 6). The stress gradient defined by salinity, $\mathrm{pH}$ and width of macrophyte belt influences the composition of the diatom community, most probably through the availability of carbon dioxide and turbidity. If the $\mathrm{pH}$ is above 8.3 , the amount of free carbon dioxide becomes very low, and practically only bicarbonate is present ${ }^{42}$. Thus diatoms inhabiting such ponds have to utilize other carbon sources ${ }^{43}$. The lack of a macrophyte belt results in the intensive resuspension of the particles by wind-induced turbulence, causing light limitation.

The expected response of the trait diversity (i.e. convergence or divergence) to stress depends on the ecological role of the trait ${ }^{19,23}$. According to the $\mathrm{SDH}$, environmental filtering acts on traits that are important for tolerating the local environmental conditions, favouring convergence to optimal values and lowering trait diversity 


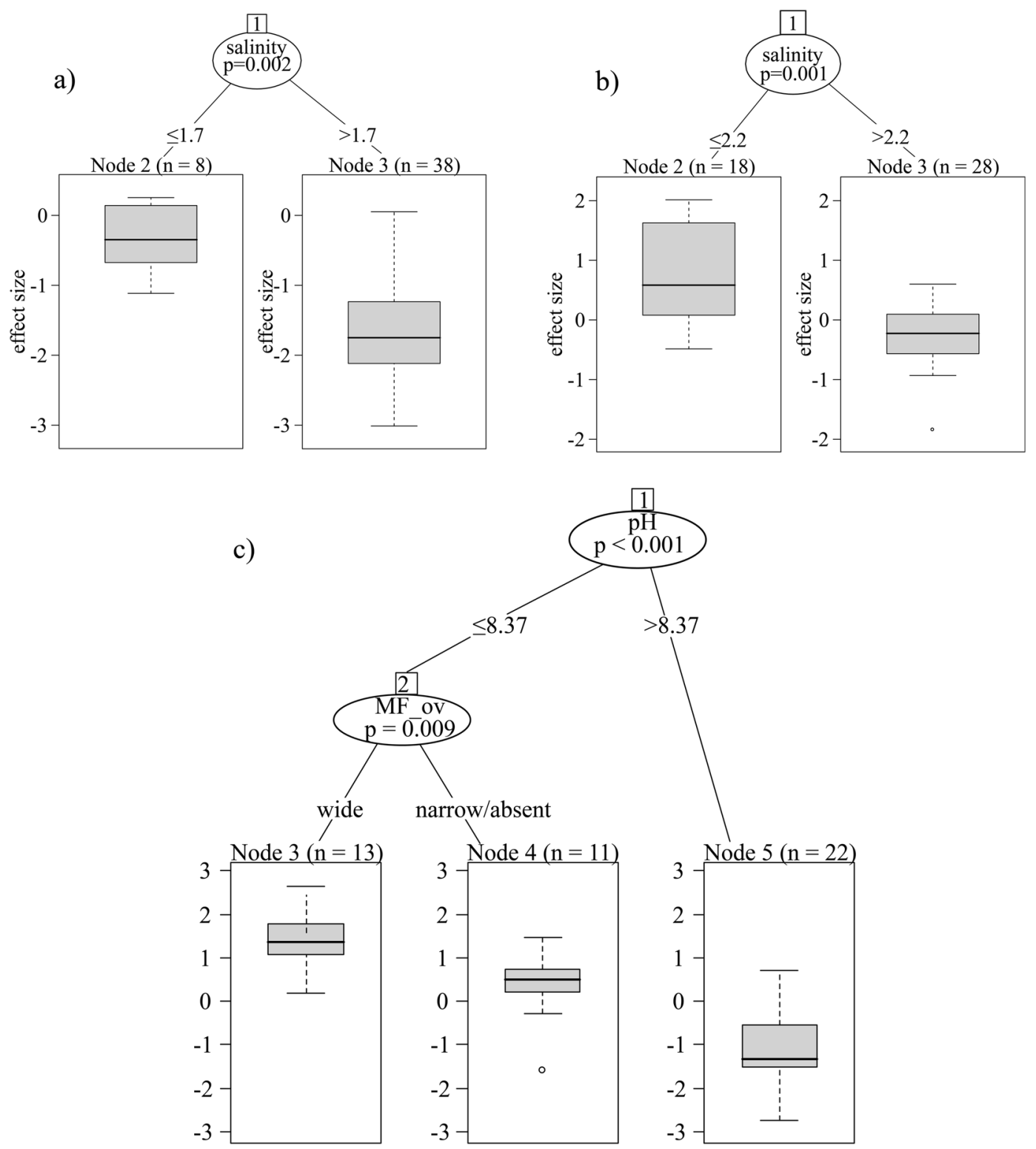

Figure 2. Dependence of effect sizes on environmental variables illustrated by the fitted conditional inference trees; (a) cell size, (b) ecological group, (c) oxygen requirement traits. $\mathrm{n}$ refers to the number of ponds belonging to the category. MP_belt: macrophyte belt.

in stressful conditions, while favouring a random trait pattern in benign environments ${ }^{19,23}$. Cell size follows this expected pattern. The convergence is predominantly caused by the increasing dominance of micro-sized $\left(100-300 \mu \mathrm{m}^{3}\right.$ ) diatoms (Fig. 3), whose reproduction and metabolic rate is high ${ }^{44}$. They can quickly utilize resources $^{45}$, have an advantage in nutrient acquisition ${ }^{46}$ and effectively convert the nitrogen into biomass ${ }^{44}$, even at low carbon dioxide concentrations.

For traits related to resource use, the SDH predicts divergence in benign environments where resource competition plays a major role in forming the species composition, and random patterns in stressed environments, where the composition is shaped by habitat filtering ${ }^{19,23}$. The ecological group followed this expected pattern (Fig. 4). Although this is not a real resource use trait, it is probably associated with resource use strategy. The transition from divergence to neutrality corresponded to the increasing dominance of diatoms with EG3. Diatoms with EG3 were equivalent to diatoms of the motile guild in the system of Rimet \& Bouchez ${ }^{40}$. A high proportion of the motile guild is frequently found in highly stressed environments ${ }^{47}$ like these ponds. Motility is a successful adaptation strategy in small aquatic environments where the algae are often exposed to harsh, adverse environmental conditions e.g. unfavourable light conditions ${ }^{48}$. Moving in the benthic mat, motile diatoms can avoid the lowered level of light and of suspended nutrients ${ }^{49}$ and can search for the most suitable habitat ${ }^{50}$.

Oxygen requirements changed from divergent to convergent along the gradient of increasing stress. This only partly supports the SDH, because it does not fit either expected pattern. At a high level of stress, TSS was high due to the lack of a wide macrophyte belt (see Supplementary Fig. S5), resulting in low light intensity, which limits the 


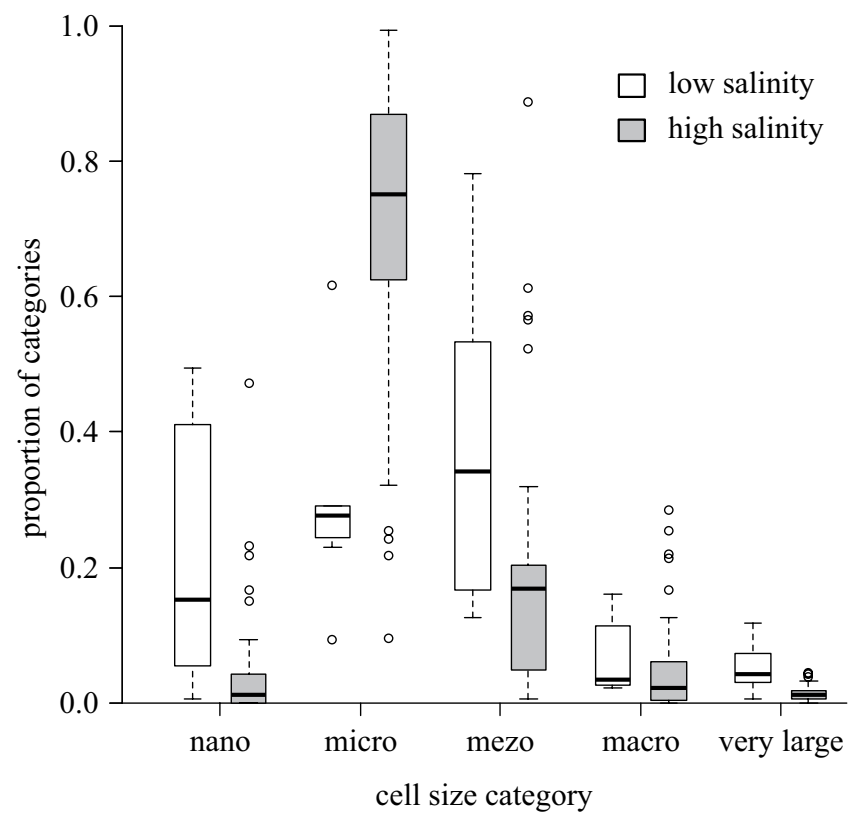

Figure 3. Proportion of cell size categories in ponds with low (white boxes) and high (grey boxes) salinity. Salinity categories correspond to two groups in Fig. 2a, i.e. high salinity here refers to values above $1.7 \mathrm{mg} \mathrm{L}^{-1}$. According to the Wilcoxon rank-sum test, the difference between the two groups is significant $\left(\mathrm{p}<2.2 * 10^{-16}\right)$ for all cell size categories.

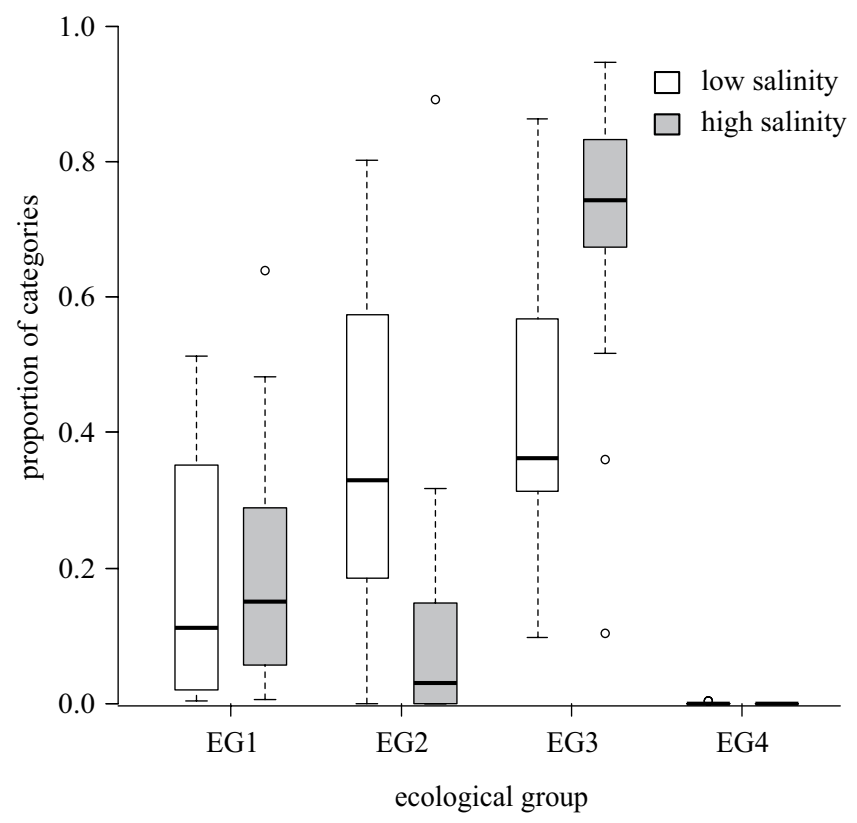

Figure 4. Proportion of ecological group categories in ponds with low (white boxes) and high (grey boxes) salinity. Salinity categories correspond to two groups in Fig. 2b, i.e. high salinity here refer to values above $2.2 \mathrm{mg} \mathrm{L}^{-1}$. According to the Wilcoxon rank-sum test, the difference between two groups is significant $\left(\mathrm{p}<2.2^{*} 10^{-16}\right)$ for all ecological group categories.

photosynthesis and oxygen production. Therefore, diatom species with a high oxygen requirement cannot exist there, and so species with a moderate or low oxygen requirement became dominant. In the most benign environment (low $\mathrm{pH}$ and a wide macrophyte belt), the oxygen requirement was divergent, in spite of the dominance of the poly-oxybiontic group (Fig. 5). Species with different oxygen requirements also use different carbon sources, thus oxygen requirement is a proxy of other traits related to resource use. Oxygen requirement is an example of traits that cannot be clearly classified into the two categories of resource use and stress tolerance traits. In stressed environments species with a high oxygen requirement are filtered out; therefore this trait behaves as a stress 


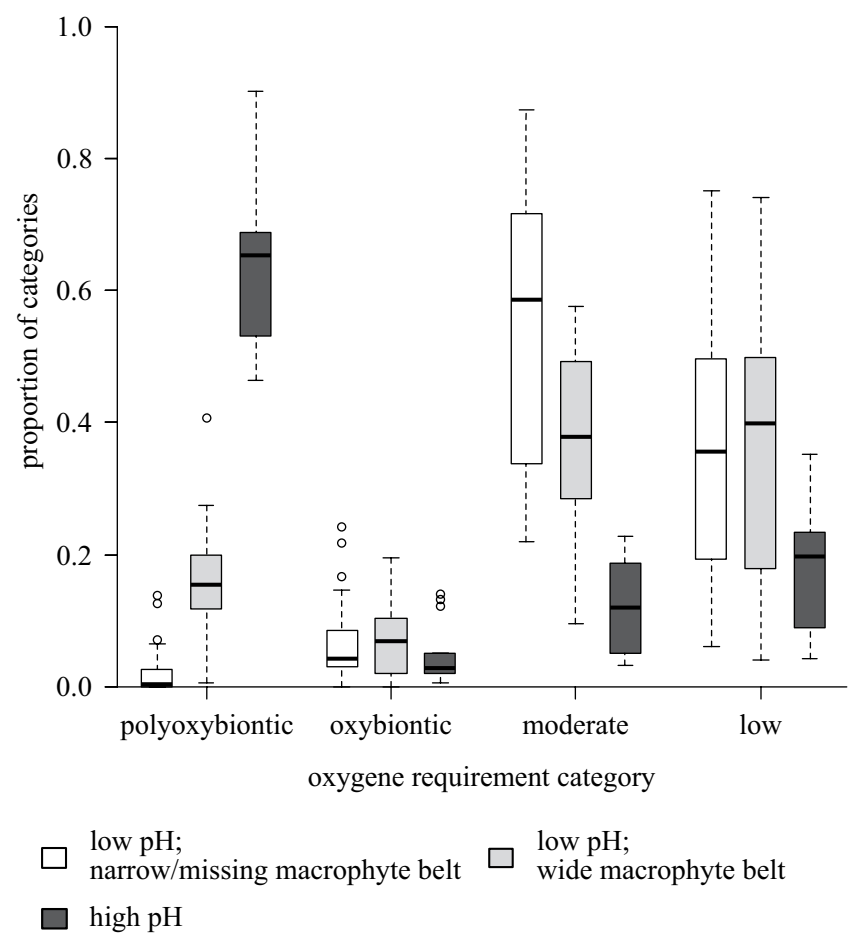

Figure 5. Proportion of oxygen requirement categories in ponds with high (white boxes) and low $\mathrm{pH}$ and a narrow/missing (light grey boxes) or wide macrophyte belt (dark grey boxes). The tree categories correspond to tree groups in Fig. $2 \mathrm{c}$ (i.e. high $\mathrm{pH}$ here refer to values above 8.37). According to the Kruskal-Wallis, there are significant differences among groups in the relative abundance of poly-oxybiont species $\left(\mathrm{p}=1.842^{*} 10^{-8}\right)$, and species with moderate $\left(\mathrm{p}=1.608 * 10^{-6}\right)$ and low $(\mathrm{p}=0.04659)$ oxygen demand, while the relative abundance of oxybiont species varies significantly among groups $(\mathrm{p}=0.685)$. Significant differences are indicated by different letters above the boxes.

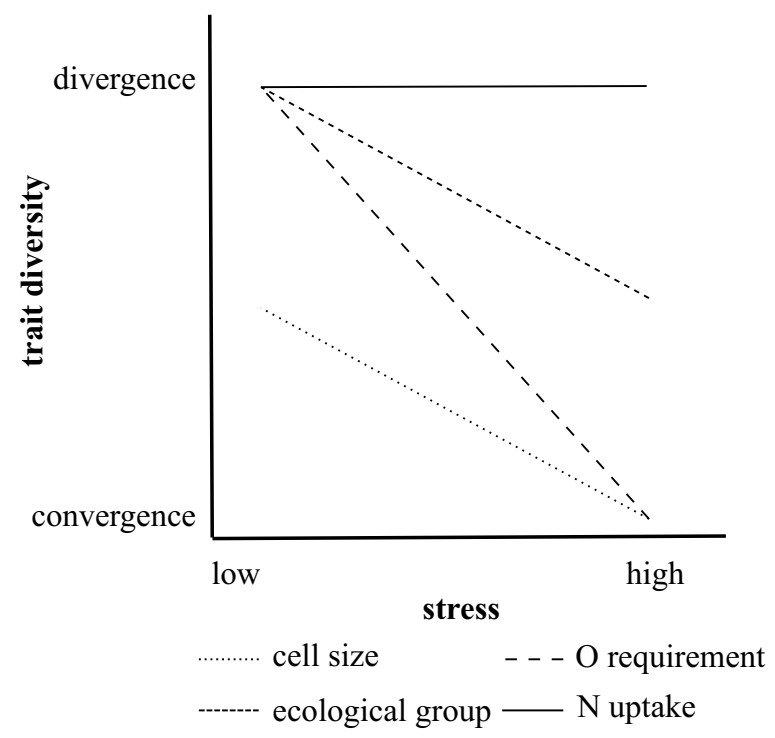

Figure 6. Summary of the observed changes in trait diversity along the stress gradient.

tolerance trait here. On the other hand, in benign environments, it behaves like a resource use trait, due to its correlation with other resource use traits.

Finally, the $\mathrm{N}$-uptake strategy trait showed divergence in almost all ponds irrespective of environmental conditions. This is in accordance with the finding that limiting similarity causes divergence in traits related to resource use ${ }^{15}$. However, the relative abundance of $\mathrm{N}$-uptake categories changed considerably. Sensitive $\mathrm{N}$-autotrophic species could reach high relative abundance if the macrophyte belt was wide, and had a low relative abundance in other cases, especially if the $\mathrm{pH}$ was high (>8.37) (see Supplementary Fig. S7a). At high pH 
( $>8.5$ ), the bioavailable nitrogen concentration is low relative to the phosphorus concentration ${ }^{51}$, because of the intensive ammonia gas exhalation. The relative abundance of facultative N-heterotrophic species was low in all ponds, but significantly higher if the macrophyte belt was absent (see Supplementary Fig. S7b). The relative abundance of obligatory $\mathrm{N}$-heterotrophic species was related to salinity: it was low if salinity was below $2.6 \mathrm{gL}^{-1}$ (see Supplementary Fig. S7c), and high if salinity was higher. In ponds with higher salinity $\left(>2.6 \mathrm{gL}^{-1}\right)$ and $\mathrm{pH}$, nitrification is inhibited, so the denitrification increases nitrogen limitation ${ }^{52}$. This can be an explanation for the significant negative correlation between $\mathrm{pH}$ and the N:P ratio (see Supplementary Table S2). Moreover, in those ponds where the macrophyte belt was absent, diatoms could switch to heterotrophic metabolism as a response to low light intensity (TSS content is high in these ponds).

Until now, the SDH has only been tested in terrestrial communities, mainly in plant communities ${ }^{17,18,26,27,53-56}$, but Patric \& Steven $s^{57}$ have tested it in bat communities, and Kruk et al. ${ }^{28}$ in phytoplankton. Some studies support the SDH, while others have not found the expected pattern or have found the opposite.

According to our knowledge, this study is the first attempt to test the stress-dominance hypothesis in an aquatic environment. The most important conclusions of this study are the following:

- Cell size, a trait related only to stress tolerance, followed the SDH prediction: this is random in a benign environment and convergent in a stressed one.

- Ecological group, related to resource use, also followed the expected pattern of transition from divergence to a random pattern along the stress gradient

- Oxygen requirement, another limiting similarity, remained the dominant force forming a trait composition even in a strongly stressed environment, and thus showed divergence irrespective of the level of stress.

- Oxygen requirement cannot be obviously categorized into the two trait categories, since at low stress it behaves like a resource use trait, while at high stress it behaves as a stress tolerance trait; thus it shows patterns unpredicted by the SDH.

The controversial results in the literature could be caused by the fact that the stress gradient studied was too short, or that even the most extreme environment was not harsh enough, or that the studied trait was not responsive to the stress gradient studied. Moreover, it is also possible that the functional convergence/divergence along the stress gradient is idiosyncratic, i.e. that the SDH is valid only under specific circumstances. In such a situation, meta-analysis based on numerous case studies may help to uncover the regularities. Such meta-analysis should be based on many case studies covering a broad range of situations, including a broad range of habitat types. This study broadens the range of habitat types which could be included.

\section{Material and Methods}

Study area. The study area is situated in the northernmost part of the Kiskunság National Park $\left(47^{\circ} 7.403^{\prime} \mathrm{N}\right.$ $19^{\circ} 8.187^{\prime} \mathrm{E}$ ), near the village of Apaj, in the plain of the Danube-Tisza Interfluve, Central Hungary, in an area of approximately $0.25 \mathrm{~km}^{2}$. The ponds developed in bomb craters can be characterized by varying areal extent, depth and salinity, conductivity, plant coverage and width of macrophyte belt. A more detailed description is presented in Vad et al. ${ }^{33}$.

Sampling, water chemical analysis and microscopy investigations. Epiphytic diatom samples were taken from green common reed (Phragmites australis) stems, or, if it was absent, from alkali bulrush (Bolboschoenus maritimus) or narrowleaf cattail (Typha angustifolia) between 7 and 9 May 2014, following the recommendations of Bolla et al. ${ }^{58}$, in 48 ponds, resulting in a dataset which is heterogeneous in environmental factors (salinity, turbidity, $\mathrm{pH}$, total phosphorus and nitrogen to phosphorus ratio; see Supplementary Table S1). A ten-centimetre section (or the maximal length in ponds with a depth of less than $10 \mathrm{~cm}$ ) of the stems was cut, starting at $10 \mathrm{~cm}$ below the water surface. Stems were chosen randomly in five replicates per pond and treated as a composite sample.

In our study, we used those environmental variables which were significant drivers of community composition in a previous RDA analysis (not shown here). The water depth and diameter of each pond, along with the percentages of open water surface and macrophyte coverage (submerged and emergent plants were considered separately) were recorded in situ. Besides, we grouped the ponds into three categories based on the size of the surrounding macrophyte belt: wide (wider than approximately $30 \%$ of the diameter of the pond), narrow (narrower than approximately $30 \%$ of the diameter of the pond) and absent (cover not exceeding $10 \%$ and not forming a belt).

We used Eutech Cyber Scan PCD 650 (Eutech Instruments Europe B.V., Landsmeer, The Netherlands) field equipment for the in situ determination of $\mathrm{pH}$ and conductivity. The methods used to determine the concentration of total suspended solids (TSS), total phosphorus (TP), nitrate-nitrogen $\left(\mathrm{NO}_{3}-\mathrm{N}\right)$, ammonium-nitrogen $\left(\mathrm{NH}_{4}-\mathrm{N}\right)$ and chlorophyll $a(\mathrm{Chl} a)$ were described in Vad et al. ${ }^{33}$. In our study, we used dissolved inorganic nitrogen (DIN) data derived from the summarized concentrations of nitrate- and ammonium-nitrogen ${ }^{33}$. At least 400 valves were counted and identified to species level with an Olympus IX70 inverted microscope equipped with differential interference contrast (DIC) optics at a magnification of $1500 \times$ to estimate the relative abundance of each taxon in the sample. Further details of the microscopy investigation and diatom preparation methods are available in $\mathrm{Vad}$ et al. $^{33}$.

Trait data. We used four traits: ecological group related to ecological guilds ${ }^{40,78}$, cell size $e^{41}$, oxygen requirement $^{30}$ and $\mathrm{N}$-uptake strategy ${ }^{30}$.

Pass $^{30}$ segregated diatom growth morphologies into three ecological guilds, based on their ability to use nutrient resources and their resistance to physical perturbation. The low profile guild contains diatoms of short 
stature attaching strongly to the surface. These diatoms can withstand resource limitation (nutrient, light) and disturbance (water current, grazers). Diatoms in the high profile guild have tall stature and attach weakly to the surface. They have superior competitive abilities in resource-rich but low disturbance habitats. The motile guild encompasses species displaying active, regulated movement within the benthic habitat. Movement is coupled to mucilage secretion and substratum adhesion along the slit in the cell wall (raphe) characteristic of motile spe$\operatorname{cies}^{30}$. Members of the motile guild are physically capable of selecting the most suitable habitat and avoiding stress by moving in the benthic mat. This latter guild comprises mostly eutrophic and pollution tolerant species and they are superior competitors for nutrients in nutrient-rich environments ${ }^{30}$.

The guild classification proposed by Passy $^{30}$ and modified by Rimet \& Bouchez ${ }^{40}$ was originally developed for rivers, but it is also applicable in lentic habitats ${ }^{59}$. Because the guild has another meaning in animal ecology ${ }^{39}$, we use the term ecological group (as proposed by Tapolczai et al. ${ }^{39}$ ).

The ecological group can reflect the trade-off between stress tolerance and competitive dominance. It can be hypothesized that in stressful conditions diatoms with an EG1 trait (corresponding to the low profile guild) become dominant, while in more favourable environments diatoms with superior competitive capabilities (trait categories EG2 and EG3, equivalent to high profile and motile guilds, respectively) become more abundant. The relative abundance of EG4 (corresponding to the planktic guild) is low in small water bodies, because of the absence of phytoplankton.

According to the allometric theor ${ }^{60}$, cell size is the major determinant of the specific physiological activities of alga ${ }^{6}$ such as growth, nutrient uptake and light capture. Small cells can be more efficient in utilizing low light or limited nutrients, and thus become dominant in more stressful environments ${ }^{61}$. In contrast, in more favourable conditions large cells have superior competitive abilities. Accordingly, trait diversity would be low at both ends of the stress gradient. The correlation of the mean relative surface areas and surface/volume ratio (S/V) with abiotic factors were very similar to the mean biovolumes of diatoms ${ }^{62}$. Stenger-Kovács et al. ${ }^{59}$ used the length/width ratio (L/W) beside the biovolume as a morphological trait, but salinity can significantly affect the valve morphology; however the effects can be different in the different species: length and width or only width can be significantly affected $^{63}$, so we do not consider using this trait to be a good decision.

Oxygen is produced by photosynthesis, which is influenced by light, temperature and nutrient levels. In light-limited habitats (such as in soda ponds where the content of suspended solids is high) diatoms may rely on heterotrophic metabolism ${ }^{64}$ shifting from oxygen producers to oxygen consumers. Van Dam et al..$^{30}$ established a classification of the oxygen requirements of diatoms based on the minimum oxygen concentration of waters that species need. The oxygen requirement trait is related to stress tolerance. In a habitat that is stressful due to a low oxygen concentration, diatoms with a low oxygen requirement will be dominant and species with a high oxygen requirement will be missing; therefore, the diversity of this trait will be low. Conversely, under favourable conditions diatoms requiring a higher oxygen concentration could also become abundant, resulting in an increase in trait diversity.

Several studies have shown that diatoms are able to assimilate organic nitrogen compounds e.g. ${ }^{65}$. Heterotrophic nitrogen-uptake serves as an additional source of nitrogen for diatoms, particularly under nitrogen-poor conditions, which may occur in soda waters ${ }^{66}$. Diatoms with this ability are nitrogen-heterotrophic, while diatoms that can utilize only inorganic nitrogen are nitrogen-autotrophic ${ }^{30}$. In stressful environments, the ability of heterotrophic nitrogen-uptake is advantageous, allowing nitrogen-heterotrophic diatoms to be dominant. In favourable conditions, nitrogen-autotrophic taxa could be successful. Thus, trait diversity would be low in a stressful environment, but high in a benign one.

We used the term 'ecological group' based on the system proposed by Rimet $\&$ Bouche $^{40}$ (the use of the term 'guild' was changed according to the Tapolczai et al. ${ }^{40}$, as we mentioned above). For cell size, the categories were those determined by Lange, Townsend, \& Matthaei ${ }^{41}$, for oxygen requirement and nitrogen uptake strategy the classifications of van Dam et al. ${ }^{30}$ were applied. The values of these traits were obtained from the OMNIDIA 6.0.2 database ${ }^{67}$.

Statistical analysis. If traits vary independently among species, observed patterns for each trait can be interpreted separately. On the other hand, in pairs of correlated traits, effects forming the distribution of a trait can also indirectly affect another through the correlation between them. Associations between traits were tested by Chi-square statistics. Since the assumption that binomial distribution can be approximated by normal distribution was not satisfied for some rare combinations, p-values were calculated by a randomization test. If the Chi-square statistic showed a significant association, Freeman-Tukey deviates were calculated to explore trait combinations which were significantly more/less frequent than expected. Correlations between environmental variables were tested using Spearman's rank correlation.

Dissimilarity matrices of species were calculated for each trait separately, applying Gower distances which can handle ordered (cell size, $\mathrm{N}$ uptake, oxygen requirement) and unordered (ecological group) categorical data ${ }^{68,69}$, using Eq. $2 \mathrm{a}$ and $2 \mathrm{~b}$ in Podani ${ }^{68}$ for ordered traits. Functional diversity was calculated from these dissimilarity matrices and species' relative abundances, applying Rao's quadratic entropy ${ }^{70}$. Instead of separately testing trait convergence due to environmental filtering and trait divergence due to competition, we needed a procedure that can measure the strength of both processes. Therefore, during randomization trait values were reshuffled among species ${ }^{15}$. Botta-Dukát \& Czúcz ${ }^{12}$ referred to this type of randomization as between plot randomization. Their simulation studies proved that this test can detect the existing trait convergence due to environmental filtering if the dataset covers a wide range of environmental variables, and can also detect the existing divergence due to competition if there is no direct or indirect effect of environmental filtering on that trait in that environment ${ }^{12}$. Probabilities of type I error (p-values) were estimated for each plot separately from 9999 random communities.

Since the distribution of Rao's quadratic entropy in the randomized communities were often highly right-skewed ${ }^{18}$, standardized effect $\operatorname{sizes}^{71}$ are inappropriate to measure the strength of convergence/ 
divergence ${ }^{11,72}$. Therefore we followed the approach suggested by Botta-Dukát ${ }^{73}$ and used probit-transformed p-values, (hereafter called effect size) as dependent variables in the subsequent analyses. Probit-transformation transforms probabilities into a minus infinity to infinity range ${ }^{74}$. If the null-distribution is Gaussian, the calculated effect size is asymptotically equal to Gotelli's standardized effect size (SES) ${ }^{71}$, and if the null-hypothesis is true, the effect size follows standard normal distribution even when the null-distribution is highly skewed. To reveal the overall (i.e. not regarding position along environmental gradients) convergence/divergence pattern, the departure of the mean effect size from zero was tested by a one-sample t-test.

To describe trait composition, Ricotta \& Moretti ${ }^{75}$ recommended quantifying both the mean and the dispersion of the trait values. While Rao's quadratic entropy quantifies dispersion ${ }^{76}$, for categorical traits the community weighted mean (CWM) can be calculated for binary dummy variables instead of the categorical variables themselves, resulting in the relative abundance of each category.

Due to the large number of potentially important environmental variables (13 variables), the relationships between them and the effect size values were explored by fitting conditional inference-based decision trees. Decision trees (also known as classification and regression trees ${ }^{77}$ ) are non-parametric statistical methods that can handle nonlinear relationships and mixed type (i.e. both categorical and continuous) independent variables, even if there is multicollinearity among them, and their results are easy to interpret ${ }^{78}$. The selected algorithm offers unbiased variable selection and a statistically sound stopping rule using p-values corrected for the effect of simultaneous hypothesis testing ${ }^{79}$, which eliminates the variable selection bias and problems of under- and over-fitting. The relative abundance of trait categories (i.e. CWM) in groups resulting from decision trees were compared by Wilcoxon (for two groups) or Kruskal-Wallis tests (for more than two groups). Note that relative abundances are summed to unity, therefore tests are not independent.

All analyses were done in an R 3.1.1 environment ${ }^{80}$ using 'party' ${ }^{80}$ and 'FD' ${ }^{81}$ add-on packages.

\section{Data availability}

Raw data are archived in Harvard Dataverse (https://doi.org/10.7910/DVN/FGXN5V, available at https://doi. org/10.7910/DVN/FGXN5V).

Received: 23 May 2019; Accepted: 16 October 2019;

Published online: 31 October 2019

\section{References}

1. Keddy, P. A. Assembly and response rules: two goals for predictive community ecology. J. Veg. Sci. 3, 157-164 (1992).

2. HilleRisLambers, J., Adler, P. B., Harpole, W. S., Levine, J. M. \& Mayfield, M. M. Rethinking Community Assembly through the Lens of Coexistence Theory. Annu. Rev. Ecol. Evol. Syst. 43, 227-248 (2012).

3. De Bie, T. et al. Body size and dispersal mode as key traits determining metacommunity structure of aquatic organisms. Ecol. Lett. 15, 740-747 (2012).

4. Shurin, J. B., Cottenie, K. \& Hillebrand, H. Spatial autocorrelation and dispersal limitation in freshwater organisms. Oecologia 159, 151-159 (2009).

5. Götzenberger, L. et al. Ecological assembly rules in plant communities-approaches, patterns and prospects. Biol. Rev. 87, 111-127 (2012).

6. Litchman, E. \& Klausmeier, C. A. Trait-Based Community Ecology of Phytoplankton. Annu. Rev. Ecol. Evol. Syst. 39, 615-639 (2008).

7. Liu, J., Soininen, J., Han, B.-P. \& Declerck, S. A. J. Effects of connectivity, dispersal directionality and functional traits on the metacommunity structure of river benthic diatoms. J. Biogeogr. 40, 2238-2248 (2013).

8. Klais, R., Norros, V., Lehtinen, S., Tamminen, T. \& Olli, K. Community assembly and drivers of phytoplankton functional structure. Funct. Ecol. 31, 760-767 (2017).

9. Weithoff, G. \& Beisner, B. E. Measures and Approaches in Trait-Based Phytoplankton Community Ecology - From Freshwater to Marine Ecosystems. Front. Mar. Sci. 6, 40 (2019).

10. Kraft, N. J. B. et al. Community assembly, coexistence and the environmental filtering metaphor. Funct. Ecol. 29, 592-599 (2015).

11. Bernard-Verdier, M. et al. Community assembly along a soil depth gradient: contrasting patterns of plant trait convergence and divergence in a Mediterranean rangeland. J. Ecol. 100, 1422-1433 (2012).

12. Botta-Dukát, Z. \& Czúcz, B. Testing the ability of functional diversity indices to detect trait convergence and divergence using individual-based simulation. Methods Ecol. Evol. 7, 114-126 (2016).

13. MacArthur, R. \& Levins, R. The Limiting Similarity, Convergence, and Divergence of Coexisting Species. Am. Nat. 101, 377-385 (1967).

14. Pásztor, E., Botta-Dukát, Z., Czárán, T., Magyar, G. \& Meszéna, G. Theory based ecology. The Darwinian approach. (Oxford Uninersity Press, 2016)

15. Stubbs, W. J. \& Wilson, J. B. Evidence for limiting similarity in a sand dune community. J. Ecol. 92, 557-567 (2004).

16. Swenson, N. G. \& Enquist, B. J. Opposing assembly mechanisms in a Neotropical dry forest: implications for phylogenetic and functional community ecology. Ecology 90, 2161-2170 (2009).

17. Carboni, M. et al. Changes in trait divergence and convergence along a productivity gradient in wet meadows. Agric. Ecosyst. Environ. 182, 96-105 (2014).

18. Lhotsky, B. et al. Changes in assembly rules along a stress gradient from open dry grasslands to wetlands. J. Ecol. 104, 507-517 (2016).

19. Lopez, B. E. et al. A new framework for inferring community assembly processes using phylogenetic information, relevant traits and environmental gradients. One Ecosyst. 1, e9501 (2016).

20. Weiher, E. \& Keddy, P. A. Assembly Rules, Null Models, and Trait Dispersion: New Questions from Old Patterns. Oikos 74, 159-164 (1995).

21. Grime, J. P. Trait convergence and trait divergence in herbaceous plant communities: Mechanisms and consequences. J. Veg. Sci. 17, $255-260$ (2006)

22. Navas, M. \& Violle, C. Plant traits related to competition: how do they shape the functional diversity of communities? Community Ecol. 10, 131-137 (2009).

23. Coyle, J. R. et al. Using trait and phylogenetic diversity to evaluate the generality of the stress-dominance hypothesis in eastern North American tree communities. Ecography 37, 814-826 (2014). 
24. Swenson, N. G. \& Enquist, B. J. Ecological and evolutionary determinants of a key plant functional trait: wood density and its community-wide variation across latitude and elevation. Am. J. Bot. 94, 451-459 (2007).

25. Mason, N. W. H., de Bello, F., Doležal, J. \& Lepš, J. Niche overlap reveals the effects of competition, disturbance and contrasting assembly processes in experimental grassland communities. J. Ecol. 99, 788-796 (2011).

26. Pakeman, R. J. Functional diversity indices reveal the impacts of land use intensification on plant community assembly. J. Ecol. 99, $1143-1151$ (2011).

27. Mason, N. W. H. et al. Changes in coexistence mechanisms along a long-term soil chronosequence revealed by functional trait diversity. J. Ecol. 100, 678-689 (2012).

28. Kruk, C. et al. Functional redundancy increases towards the tropics in lake phytoplankton. J. Plankton Res. 39, 518-530 (2017).

29. Economou-Amilli, A. Periphyton analysis for the evaluation of water quality in running waters of Greece. Hydrobiologia 74, 39-48 (1980).

30. Van Dam, H., Mertens, A. \& Sinkeldam, J. A coded checklist and ecological indicator values of freshwater diatoms from The Netherlands. Netherland J. Aquat. Ecol. 28, 117-133 (1994).

31. Kelly, M. et al. A comparison of national approaches to setting ecological status boundaries in phytobenthos assessment for the European Water Framework Directive: results of an intercalibration exercise. Hydrobiologia 621, 169-182 (2009).

32. Kelly, M. G., King, L., Jones, R. I., Barker, P. A. \& Jamieson, B. J. Validation of diatoms as proxies for phytobenthos when assessing ecological status in lakes. Hydrobiologia 610, 125-129 (2008).

33. Vad, C. F. et al. Wartime scars or reservoirs of biodiversity? The value of bomb crater ponds in aquatic conservation. Biol. Conserv. 209, 253-262 (2017)

34. Remane, A. Die Brackwasserfauna (mit besonderer Berücksichtigung des Ostseegebietes). Zool Anz Suppl 7, 34-74 (1934).

35. Mittelbach, G. G. et al. What Is the Observed Relationship Between Species Richness and Productivity? Ecology 82, 2381-2396 (2001).

36. Chase, J. M. \& Leibold, M. A. Spatial scale dictates the productivity-biodiversity relationship. Nature 416, 427-430 (2002).

37. Borics, G. et al. The role of phytoplankton diversity metrics in shallow lake and river quality assessment. Ecol. Indic. 45, 28-36 (2014).

38. Horváth, Z. et al. Opposing patterns of zooplankton diversity and functioning along a natural stress gradient: when the going gets tough, the tough get going. Oikos 123, 461-471 (2014).

39. Tapolczai, K., Bouchez, A., Stenger-Kovács, C., Padisák, J. \& Rimet, F. Trait-based ecological classifications for benthic algae: review and perspectives. Hydrobiologia 776, 1-17 (2016).

40. Rimet, F. \& Bouchez, A. Life-forms, cell-sizes and ecological guilds of diatoms in European rivers. Knowl Managt Aquat. Ecosyst https://doi.org/10.1051/kmae/2012018 (2012).

41. Lange, K., Townsend, C. R. \& Matthaei, C. D. A trait-based framework for stream algal communities. Ecol. Evol. 6, $23-36$ (2016).

42. Wurts, W. A. \& Durborow, R. M. Interactions of $\mathrm{pH}$, carbon dioxide, alkalinity and hardness in fish ponds. South. Reg. Aquac. Cent. Publ. 464, 1-4 (1992)

43. Tortell, P. D., Reinfelder, J. R. \& Morel, F. M. M. Active uptake of bicarbonate by diatoms. Nature 390, 243-244 (1997).

44. Marañón, E. et al. Unimodal size scaling of phytoplankton growth and the size dependence of nutrient uptake and use. Ecol. Lett. 16, 371-379 (2013).

45. Reynolds, C. S. The Ecology of Phytoplankton, https://doi.org/10.1017/CBO9780511542145 (Cambridge University Press, 2006).

46. Sommer, U., Charalampous, E., Genitsaris, S. \& Moustaka-Gouni, M. Benefits, costs and taxonomic distribution of marine phytoplankton body size. J. Plankton Res. 39, 494-508 (2017).

47. Stenger-Kovács, C. et al. Vanishing world: alkaline, saline lakes in Central Europe and their diatom assemblages. Inland Waters 4, 383-396 (2014).

48. Souffreau, C., Vanormelingen, P., Sabbe, K. \& Vyverman, W. Tolerance of resting cells of freshwater and terrestrial benthic diatoms to experimental desiccation and freezing is habitat-dependent. Phycologia 52, 246-255 (2013).

49. Cohn, S. A. \& Weitzell, R. E. Ecological Considerations of Diatom Cell Motility. I. Characterization of Motility and Adhesion in Four Diatom Species1. J. Phycol. 32, 928-939 (1996).

50. Passy, S. I. Diatom ecological guilds display distinct and predictable behavior along nutrient and disturbance gradients in running waters. Aquat. Bot. 86, 171-178 (2007).

51. Boros, E., Ecsedi, Z. \& Ola' 'h, J. editors. Ecology and management of soda pans in the Carpatian Basin. (Hortobágy Environmental Association, 2013).

52. Sorokin, D. Y. et al. Microbial diversity and biogeochemical cycling in soda lakes. Extremophiles 18, 791-809 (2014).

53. Butterfield, B. J., Bradford, J. B., Munson, S. M. \& Gremer, J. R. Aridity increases below-ground niche breadth in grass communities. Plant Ecol. 218, 385-394 (2017).

54. Gastauer, M., Saporetti-Junior, A. W., Valladares, F. \& Meira-Neto, J. A. A. Phylogenetic community structure reveals differences in plant community assembly of an oligotrophic white-sand ecosystem from the Brazilian Atlantic Forest. Acta Bot. Bras. 31, 531-538 (2017)

55. Miazaki, A. S., Gastauer, M. \& Meira-Neto, J. A. A. Environmental severity promotes phylogenetic clustering in campo rupestre vegetation. Acta Bot. Bras. 29, 561-566 (2015).

56. Simova, I. et al. Shifts in trait means and variances in North American tree assemblages: species richness patterns are loosely related to the functional space. Ecography 38, 649-658 (2015).

57. Patrick, L. E. \& Stevens, R. D. Phylogenetic community structure of North American desert bats: influence of environment at multiple spatial and taxonomic scales. J. Anim. Ecol. 85, 1118-1130 (2016).

58. Bolla, B. et al. Recommendations for ecological status assessment of Lake Balaton (largest shallow lake of Central Europe), based on benthic diatom communities. Vie Milieu 60, 197-208 (2010).

59. Stenger-Kovács, C. et al. Expanding the trait-based concept of benthic diatoms: Development of trait- and species-based indices for conductivity as the master variable of ecological status in continental saline lakes. Ecol. Indic. 95, 63-74 (2018).

60. West, G. B., Brown, J. H. \& Enquist, B. J. A general model for the structure and allometry of plant vascular systems. Nature 400, 664-667 (1999)

61. Litchman, E. et al. Linking traits to species diversity and community structure in phytoplankton. Hydrobiologia 653, 15-28 (2010).

62. Neustupa, J., Veselá, J. \& Št'astný, J. Differential cell size structure of desmids and diatoms in the phytobenthos of peatlands. Hydrobiologia 709, 159-171 (2013).

63. Trobajo, R., Rovira, L., Mann, D. G. \& Cox, E. J. Effects of salinity on growth and on valve morphology of five estuarine diatoms. Phycol. Res. 59, 83-90 (2011).

64. Tuchman, N. C., Schollett, M. A., Rier, S. T. \& Geddes, P. Differential heterotrophic utilization of organic compounds by diatoms and bacteria under light and dark conditions. Hydrobiologia 561, 167-177 (2006).

65. Hellebust, J. A. \& Lewin, J. Heterotrophic nutrition. In The biology of diatoms (ed. Werner, D.) 169-197 (Blackwell, 1977).

66. Boros, E. et al. The effect of aquatic birds on the nutrient load and water quality of soda pans in Hungary. Acta Zool. Acad. Sci. Hung. 54, 207-224 (2008).

67. Lecointe, C., Coste, M. \& Prygiel, J. "Omnidia": software for taxonomy, calculation of diatom indices and inventories management. Hydrobiologia 269-270, 509-513 (1993).

68. Podani, J. Extending Gower's General Coefficient of Similarity to Ordinal Characters. Taxon 48, 331-340 (1999). 
69. Podani, J. Introduction to the exploration of multivariate biological data. (Backhuys Publishers, 2000).

70. Botta-Dukát, Z. Rao's quadratic entropy as a measure of functional diversity based on multiple traits. J. Veg. Sci. 16, 533-540 (2005).

71. Gotelli, N. J. \& McCabe, D. J. Species co-occurrence: a meta-analysis of J. M. Diamond's assembly rules model. Ecology 83, 2091-2096 (2002).

72. Ulrich, W. \& Gotelli, N. J. Null model analysis of species associations using abundance data. Ecology 91, 3384-3397 (2010).

73. Botta-Dukát, Z. Cautionary note on calculating standardized effect size (SES) in randomization test. Community Ecol. 19, 77-83 (2018).

74. Dobson, A. J. An introduction to generalized linear models. (Chapman\&Hall/CRC, 2002).

75. Ricotta, C. \& Moretti, M. CWM and Rao's quadratic diversity: a unified framework for functional ecology. Oecologia 167, 181-188 (2011).

76. Champely, S. \& Chessel, D. Measuring biological diversity using Euclidean metrics. Environ. Ecol. Stat. 9, 167-177 (2002).

77. Breiman, L., Friedman, J., Ohlsen, R. \& Stone, C. Classification and regression trees. (Chapman Hall/CRC Press, 1984).

78. Crawley, M. J. The R Book. (John Wiley \& Sons, 2007).

79. Hothorn, T., Hornik, K. \& Zeileis, A. Unbiased Recursive Partitioning: A Conditional Inference Framework. J. Comput. Graph. Stat. 15, 651-674 (2006).

80. R Core Team. R: A language and environment for statistical computing. (R Foundation for Statistical Computing, 2013).

81. Laliberté, E., Legendre, P. \& Shipley, B. FD: measuring functional diversity from multiple traits, and other tools for functional ecology. R package version 1, 0-12 (2014).

\title{
Acknowledgements
}

This research was supported by the GINOP-2.3.2-15-2016-00019 and National Research, Development and Innovation Office - NKFIH, 119208 grants. The research was financed by the Higher Education Institutional Excellence Programme (20428-3/2018/FEKUTSTRAT) of the Ministry of Human Capacities in Hungary, within the framework of the 4. thematic programme of the University of Debrecen. The authors thank Judit Szönyi for her valuable comments for the manuscript.

\section{Author contributions}

É.Á. identified diatoms using S.E.M., A.F. and Z.s.T. identified diatoms using L.M. C.s.F.V. contributed to the fieldwork and sampling design, K.T.K. and A.F. carried out the sampling. P.D. performed the chemical analyses (laboratory measurements). Z.B.D. performed statistical analyses. É.Á., C.s.F.V. and K.T.K. M.D., I.G., Z.B.D. and G.B. contributed to the writing of the manuscript.

\section{Competing interests}

The authors declare no competing interests.

\section{Additional information}

Supplementary information is available for this paper at https://doi.org/10.1038/s41598-019-52304-4.

Correspondence and requests for materials should be addressed to É.Á.

Reprints and permissions information is available at www.nature.com/reprints.

Publisher's note Springer Nature remains neutral with regard to jurisdictional claims in published maps and institutional affiliations.

\begin{abstract}
Open Access This article is licensed under a Creative Commons Attribution 4.0 International License, which permits use, sharing, adaptation, distribution and reproduction in any medium or format, as long as you give appropriate credit to the original author(s) and the source, provide a link to the Creative Commons license, and indicate if changes were made. The images or other third party material in this article are included in the article's Creative Commons license, unless indicated otherwise in a credit line to the material. If material is not included in the article's Creative Commons license and your intended use is not permitted by statutory regulation or exceeds the permitted use, you will need to obtain permission directly from the copyright holder. To view a copy of this license, visit http://creativecommons.org/licenses/by/4.0/.
\end{abstract}

(C) The Author(s) 2019 